1 Chase, S. P., Ohio State Medical fournal, 1975, 70, 106.

2 Rudge, C. J., Bewick, M., and McColl, I., British Medical fournal, 1973, 3, 23.

${ }^{3}$ Shapira, M., and Stern, W. Z., fournal of the American Medical Association, 1967, 201, 327.

4 Smith, B. E., et al., Archives of Surgery, 1965, 90, 228.

5 Shafiq, M., Fournal of the Royal College of Surgeons of Edinburgh, 1975, $20,208$.

Nuffield Department of Surgery, Radcliffe Infirmary, Oxford

J. R. ALLSOP, F.R.A.C.S., Lecturer

A. R. ASKEW, F.R.C.S., Registrar

\section{Congenital heart block diagnosed antenally associated with multiple fetal abnormality}

The following report illustrates how the diagnosis of congenital heart block can be made before birth.

\section{Case Report}

A grossly abnormal female infant weighing $2040 \mathrm{~g}$ was born at 36 weeks' gestation. Two previous pregnancies had resulted in normal male term infants. The present pregnancy was uncomplicated until the 34th week, when the 25 -year-old mother was admitted with acute polyhydramnios. It was difficult to hear the fetal heart with a stethoscope and sonicaid. An abdominal $x$-ray film showed no evidence of intrauterine death or fetal abnormality. Urinary oestriol values were normal. Ultrasonic examination showed a posterofundal placenta and gross polyhydramnios. Using the time position scan, the fetal heart rate was 56 beats/min. A simultaneous recording of the maternal pulse was 120 beats/min. Amniocentesis was performed at 35 weeks gestation with the removal of $1200 \mathrm{ml}$ of clear fluid. At the same time, $9 \mathrm{ml}$ of iophendylate (Myodil) was injected into the amniotic sac. The amniogram showed the absence of contrast medium within the fetal gut but no other abnormality. A lecithin: sphingomyelin ratio was $0 \cdot 6: 1$ on the fluid obtained.

After the spontaneous onset of premature labour the fetal heart rate pattern did not alter with uterine contractions (see fig.). The intra-partum fetal electrocardiogram (E.C.G.) was recorded by connecting the fetal scalp
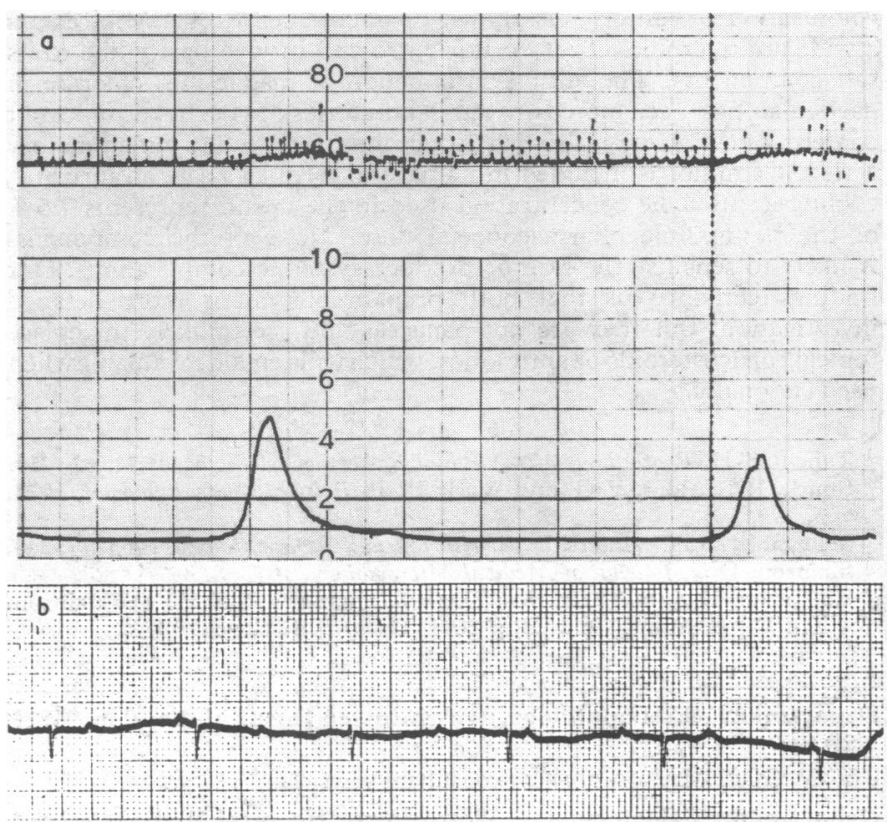

(a) Baseline bradycardia at 55 beats/min with loss of beat-to-beat variation and with no decelerations. (b) Third-degree heart block on intra-partum fetal E.C.G. electrode to a standard E.C.G. machine. It showed complete A-V dissociation consistent with third-degree heart block (see fig.). The labour and delivery were normal. The Apgar score of the infant at birth was 2 at one minute and 2 at 10 minutes. The baby gasped through a minute oral opening. She had a gross cleft palate and a cleft upper and lower lip. There was no mandible, the floor of the mouth being composed entirely of skin. Only a small nodule of tissue about $1 \mathrm{~cm}$ in diameter formed the tongue. The left ear was placed low on the skull. There was no trace of the right ear or auditory canal. Resuscitation was not possible. The infant died 15 minutes after delivery. In addition, the necropsy showed a dextrocardia and cardiac enlargement as well as a ventricular septal defect. There was agenesis of the right lung and the left lung was only partly divided into two lobes. There was complete situs inversus of the abdominal viscera with incomplete rotation of the gut and partial failure of secondary fixation of the colon. The genitourinary, endocrine, and central nervous systems were normal. The placenta weighed $460 \mathrm{~g}$ and was also normal. Viral and chromosomal studies on the infant's blood showed no abnormality.

\section{Discussion}

It is important to differentiate fetal bradycardia due to hypoxia from congenital heart block. The accepted way of investigating a fetal heart rate trace as shown in the fig. is to determine the fetal $\mathrm{pH}$ before deciding on whether or not to perform a caesarean section. The E.C.G. is only helpful in addition. An unnecessary caesarean section may thus be prevented, especially if a possible associated abnormality existed that was not compatible with extrauterine life.

Department of Obstetrics and Gynaecology, Liverpool Maternity Hospital, University of Liverpool, Liverpool

U. ABDULLA, M.B., M.R.c.o.G., Senior Lecturer and Consultant D. W. CHARTERS, M.B., M.R.C.o.G., Registrar

\section{Septic abortion in women using intrauterine devices}

It has been known for some time that women who become pregnant with an intrauterine contraceptive device (I.U.C.D.) in situ are at a greatly increased risk of spontaneous abortion. ${ }^{1}$ Furthermore, several reports were published in 1974 which suggested that such abortions are particularly likely to be septic, sometimes with fatal results for the mother. ${ }^{2}$ Most of the evidence has incriminated the Dalkon shield, ${ }^{2-4}$ but other devices are not entirely free from suspicion. ${ }^{5}$

We present here data relevant to this problem accumulated during a long-term prospective study of women using different methods of contraception.

\section{Patients, Methods and Results}

The methods used in our prospective study have been described elsewhere. ${ }^{1}$ In brief, 17000 married women, aged 25-39 years, were recruited at one or other of 17 family planning clinics. At entry $56 \%$ were using oral contraceptives, $25 \%$ were using a diaphragm, and $19 \%$ were using an I.U.C.D. These women are being followed up at the clinics or, when necessary, by post, telephone, or home visiting. Information collected from each woman includes details of pregnancies and their outcome and changes in contraceptive practices. Losses to follow-up at the time of writing were at the rate of about one per 100 women a year. When our analysis was undertaken, 58 spontaneous abortions had occurred among women becoming pregnant with an I.U.C.D. in situ and 57 had occurred among women experiencing an unplanned pregnancy while using some other method of contraception. In addition to examining the data routinely recorded during the study inquiries were made of general practitioners and, where appropriate, hospital consultants to try to find out whether any of these 115 abortions had been accompanied by evidence of sepsis.

The characteristics of the two groups of women suffering a spontaneous abortion are shown in the table. Those in the I.U.C.D. group were slightly younger and of slightly lower social class than those in the "other methods" group. The absence of any nulliparous women in the I.U.C.D. group was expected since almost all the I.U.C.D. users in our study have previously had children. Only four of the women in the I.U.C.D. group were definitely using a Dalkon shield. Of the remainder 34 were using a Lippes loop, 12 a Saf-T-coil, and eight a device of unknown type. We defined a septic abortion 
Characteristics of Women who Suffered Spontaneous Abortion in the Two Groups

\begin{tabular}{|c|c|c|c|c|c|c|c|c|c|c|c|c|c|c|}
\hline & & & & & \multicolumn{3}{|c|}{ Age (Years) } & \multicolumn{3}{|c|}{ No. of Previous Births } & \multicolumn{3}{|c|}{$\begin{array}{l}\text { Social Class } \\
\text { (Registrar General's Classification) }\end{array}$} & \multirow{2}{*}{ Total } \\
\hline & & & & & $25-29$ & $30-34$ & $\geqslant 35$ & 0 & $1-2$ & $\geqslant 3$ & I and II & III & IV and $V$ & \\
\hline $\begin{array}{l}\text { I.U.C.D. group , . } \\
\text { "Other methods" group }\end{array}$ & $\because$ & $\because$ & 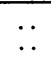 & .. & $\begin{array}{l}20 \\
21\end{array}$ & $\begin{array}{l}26 \\
17\end{array}$ & $\begin{array}{l}12 \\
19\end{array}$ & $\begin{array}{l}0 \\
9\end{array}$ & $\begin{array}{l}38 \\
26\end{array}$ & $\begin{array}{l}20 \\
22\end{array}$ & $\begin{array}{l}18 \\
26\end{array}$ & $\begin{array}{l}32 \\
22\end{array}$ & $\begin{array}{l}8 \\
9\end{array}$ & $\begin{array}{l}58 \\
57\end{array}$ \\
\hline
\end{tabular}

as one in which the woman (a) developed a temperature of $37.8^{\circ} \mathrm{C}$ or more, (b) had some local evidence of infection of the genital tract, and (c) was treated with an antibacterial drug. On this basis four of the women in the I.U.C.D. group (none of whom was using a Dalkon shield) and two in the "other methods" group suffered a septic abortion. None of these six women was seriously ill and the response to treatment was prompt in each case.

The $\mathbf{1 1 5}$ women were followed up for periods ranging from one to $\mathbf{7 2}$ months after the abortion occurred (mean periods: I.U.C.D. group, 27 months; "other methods" group, 28 months). One patient in the I.U.C.D. group and one in the "other methods" group developed salpingitis 2 and 11 months respectively after the abortion occurred. Both women were admitted to hospital, and both responded promptly to treatment with ampicillin.

\section{Comment}

While the present analysis concerns only 58 spontaneous abortions in women with an I.U.C.D. in situ an appropriate control group was available for comparison. The findings certainly give no cause for alarm. It should be noted however, that only four of the abortions were in women using a Dalkon shield.

${ }^{1}$ Vessey, M. P. et al., Lancet, 1974, 1, 495.

2 Templeton, J. S., British Medical fournal, 1974, 2, 612.

3 Tatum, H. J. et al., Contraception, 1975, 11, 465.

4 British Medical fournal, 1975, 2, 458.

5 International Family Planning Digest, 1975, 1, 12.

Department of the Regius Professor of Medicine, Radclifie Infirmary,
Oxford OX2 6HE
PETER WILLIAMS, B.M., B.CH., M.R.C. Research Fellow
Department of Social and Community Medicine, Oxford
University, Oxford OX1 3QN
BRIDGET JOHNSON, B.A., Research Assistant
MARTIN VESSEY, M.D., F.F.C.M., Professor

\section{New non-steroid non-antibiotic skin medicaments}

Common skin diseases are now usually treated topically with corticosteroids and antibiotics. But the indiscriminate use of these valuable agents is dangerous. The chief ill effects of corticosteroids are becoming well known, ${ }^{1}$ and the casual application of antibiotics is responsible for much allergic skin sensitisation and for selection of antibioticresistant organisms in and out of hospital. ${ }^{2}$ Because of these problems, as well as the relatively high cost of most currently available preparations, we have examined cheap, safe alternatives.

\section{Method and results}

Traditional formulations such as those containing ichthammol, starch, silver nitrate, potassium permanganate, Eusol, or the antiseptic dyes are messy and often ineffective, but we have obtained promising results with two clean, colourless preparations. The compositions of Miol lotion and cream (Comprehensive Pharmaceuticals Ltd, London) are set out in the table. In most cases the lotion was applied repeatedly as soaks during the first day, and then the more convenient cream was used for at least two weeks. All other local or systemic dermatological medication was stopped during the treatment. In the case of leg ulcers, however, limb elevation and bandaging or supportive hosiery were continued.

After a short initial trial the original formulation of the cream was modified to the composition given in the table. We have subsequently treated 120 patients whose diagnoses were stasis ulcers (44), varicose eczema (36), varicose eczema with superimposed contact eczema (20), severe intertrigo (13), cutaneous angiitis (four), and single cases of Darier's disease, widespread capillary haemangioma with ulceration, and benign familial chronic pemphigus. In all cases prolonged conventional treatment with corticosteroidsoften with antibiotics-was unsuccessful. In every case the lesions were colonised by pathogenic bacteria or yeasts. Staphylococcus aureus predominated in 69 patients, Gram-negative bacilli (mainly Pseudomonas aeruginosa and Proteus spp) in 40-chiefly in leg ulcers-Candida albicans in seven, and Streptococcus pyogenes in four patients.

Compositions of Miol lotion and cream

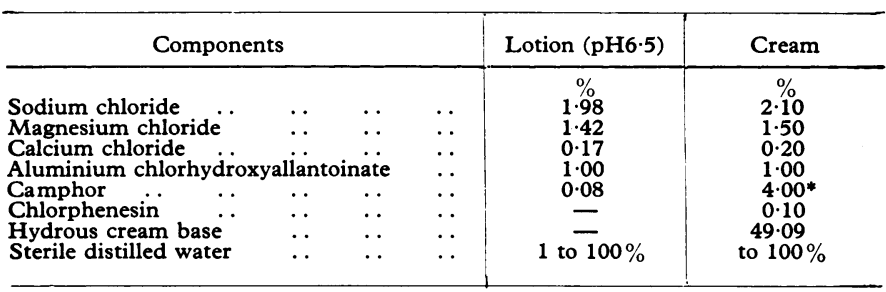

*In initial mixture; owing to volatilisation the product contains $1.5 \%$.

The preparations were well tolerated by all except four patients who complained of local pain in the margins of ulcers. Most patients gained early relief from pre-existing pruritus. In 96 patients substantial clinical improvement was maintained for at least one month. Many of the indolent ulcers healed with surprising speed as did varicose eczemas. Gram-negative bacilli were suppressed in all except three cases of leg ulcer where persistent $P_{s}$ aeruginosa paralleled an inadequate clinical response. $C$ albicans and Str pyogenes were eliminated during treatment and so was Staph aureus generally, but, as we have found using topical antibiotics, ${ }^{3}$ this organism persisted at lower population levels in 27 patients-including 13 who made satisfactory clinical progress.

\section{Discussion}

The importance of suppressing even "subclinical" microbial colonisation of lesions was shown in our earlier work. ${ }^{3}$ Miol exerts a wide antimicrobial effect both in vitro and in vivo partly due to its salt components. The antibacterial action of magnesium chloride in particular has been noted in our laboratories. ${ }^{4}$ The hypertonic salt content of Miol may also partly account for its anti-inflammatory action. Camphor is included in its natural form as a safe antipruritic, cooling agent ${ }^{5}$; the concentration used in the cream represents $7.5 \%$ of the permissible pharmacopoeial dose. None of the components is likely to sensitise the skin or produce systemic complications. Our findings convince us that both preparations merit more detailed investigation. But they are not panaceas and are unlikely to replace topical corticosteroids or antibiotics, which will remain invaluable when used rationally.

1 Tan, R S-H, Proceedings of the Royal Society of Medicine, 1974, 67, 719.

2 Smith, R J, Alder, V G, and Warin, R P, British Medical fournal, 1975, 3, 199.

3 Selwyn, S, and Chalmers, D, British fournal of Dermatology, 1965, 77, 349.

4 Shanson, D C, fournal of Medical Microbiology. 1975, 8, 357.

5 Wilkinson, D S, in Textbook of Dermatology, ed A Rook, D S Wilkinson, and F J G Ebling, 2nd ed, p 2071. Oxford, Blackwell, 1972.

Department of Dermatology, Westminster Hospital, London SW1P 2AP

P W M COPEMAN, MD, FRCP, consultant physician

Department of Bacteriology, Westminster Hospital Medical School, London SW1P 2AR

$S$ SELWYN, MD, MRCPATH, reader in medical microbiology and consultant bacteriologist 